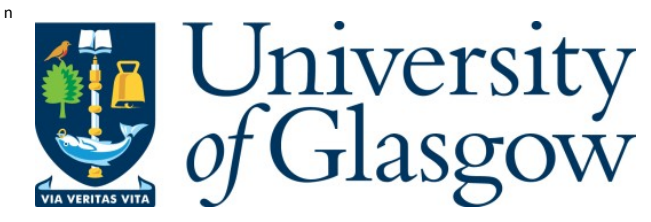

A bhayawansa, S., A leksanyan, M ., and Bahtsevangolou, J. (2015) The use of intellectual capital information by sell-side analysts in company valuation. A ccounting and Business Research . ISSN 0001-4788

Copyright @ 2015 Institute of Chartered A ccountants in England and Wales A copy can be downloaded for personal non-commercial research or study, without prior permission or charge

Content must not be changed in any way or reproduced in any format or medium without the formal permission of the copyright holder(s)

http://eprints.gla.ac.uk/101133/

Deposited on: 22 J anuary 2015

Enlighten - R esearch publications by members of the U niversity of Glasgow http://eprints.gla.ac.uk 
The use of intellectual capital information by sell-side analysts in company valuation

\section{Subhash Abhayawansa ${ }^{1}$}

School of Business, Faculty of Business and Law, Swinburne University of Technology,

Hawthorn, Australia

\section{Mark Aleksanyan}

Adams Smith Business School, University of Glasgow, Glasgow, UK

\section{John Bahtsevanoglou}

School of Business, Faculty of Business and Law, Swinburne University of Technology, Hawthorn, Australia

\section{Acknowledgements}

This research was funded through the research grant scheme of the Accounting and Finance Association of Australia and New Zealand (AFAANZ), awarded in 2010. The authors are grateful for the comments and suggestions received from participants at the IAAER International Accounting and Auditing Conference held in Amsterdam in 2012, Professor John Holland and two anonymous reviewers on previous versions of this paper.

\footnotetext{
${ }^{1}$ Corresponding author Name: Subhash Abhayawansa

Postal Address: Faculty of Business and Enterprise, Swinburne University of Technology, John Street, Hawthorn,

VIC 3122, Australia

Telephone: +61392144327

Fax: +61398192117

Email: sabhayawansa@swin.edu.au
} 


\title{
The use of intellectual capital information by sell-side analysts in company valuation
}

\begin{abstract}
This paper investigates the role of intellectual capital information (ICI) in sell-side analysts' fundamental analysis and valuation of companies. Using in-depth semi-structured interviews it penetrates the black-box of analysts' valuation decision making by identifying and conceptualising the mechanisms and rationales by which ICI is integrated within their valuation decision processes. We find that capital market participants are not ambivalent to ICI, and ICI is used: (1) to form analysts' perceptions of the overall quality, strengths and future prospects of companies; (2) in deriving valuation model inputs; (3) in setting price targets and making investment recommendations; and (4) as an important and integral element in analyst-client communications. We show that: there is a 'pecking order' of mechanisms for incorporating ICI in valuations, based on quantifiability; IC valuation is grounded in valuation theory; there are designated entry points in the valuation process for ICI; and a number of factors affect analysts' ICI use in valuation. We also identify a need to redefine 'value-relevant' ICI to include non-price sensitive information; acknowledge the boundedness and contextuality of analysts' rationality and motives of their ICI use; and the important role of analyst-client meetings for ICI communication.
\end{abstract}

Key word: Corporate reporting, interviews, intellectual capital, sell-side analysts, investment recommendations, valuation 
I would suggest $90 \%$ of conversations with clients involve some conversation about intellectual capital elements and my view of how those come together. So it's an incredibly important issue. It's just hard to quantify, but it's something that investment communities discuss to great length. (A sell-side analyst interviewed in this study)

\section{Introduction}

With the rise of the 'new economy' firms' intellectual capital (IC) is increasingly regarded as an important driver of corporate value creation and financial success (Stewart, 1997, Hand and Lev, 2003, Ashton, 2005). IC is explained in the accounting literature as a collection of attributes comprising the value embodied in people (human capital), processes (structural capital), and relationships (relational capital) of a firm (Edvinsson and Sullivan, 1996, Stewart, 1997, Sveiby, 1997, MERITUM, 2002). It is a term often used interchangeably with intangibles.

Firms investing in IC, however, often are systematically undervalued by financial markets and consequently face a higher cost of capital relative to other firms (Chan et al., 2001, Lev, 2003). It is argued that a main cause of this problem is the lack of understanding of the ICvalue relationship, resulting in an inherent uncertainty about firm value (Bukh, 2003, Johanson, 2003). Research demonstrates that relationships between IC and value are nonlinear, fluid and fragile (Cuganesan, 2005, Dumay, 2009, Murthy and Mouritsen, 2011). Sell side analysts (herein after referred to as 'analysts') purport to understand this relationship and therefore compensate for financial reporting deficiencies (Amir et al., 2003). There is strong evidence suggesting that if it were not for the contribution of analysts, the level of undervaluation of IC-intensive firms would likely be even greater (Barth et al., 2001, Amir et al., 2003). Nonetheless, there are deficiencies in the way in which analysts account for the impact of IC on future firm profitability as evidenced by analysts' forecast errors increasing with the IC intensity of the firm (Amir et al., 2003). In this paper we carry out the groundwork for a potential understanding of the current model of IC valuation utilised by analysts. i.e., we examine the mechanisms and rationales by which IC Information (ICI) is dealt with in firm valuation and investment recommendation decision-making by analysts. We also respond to Imam et al. (2008) call for research on how analysts, as actors operating within a social milieu, make use of company information to generate equity valuations.

Another motivation for this study is the asymmetry that exists between firms and capital market participants in relation to ICI, which is a cause of the undervaluation of firms particularly with high levels of IC (Amir et al., 2003). The evidence that insider gains in 
firms investing in R\&D type IC is larger than insider gains in firms with no R\&D activities (Aboody and Lev, 2000) highlights this information asymmetry. Proprietary costs affect firms' disposition towards disclosure of ICI. Deficiencies in communicating IC to the capital market are also attributed to the knowledge gap of how capital market participants use ICI to value firms (Bukh, 2003, Mouritsen, 2003, Holland, 2004). Holland (2004) identifies the existence of an IC communication barrier resulting from a mismatch between companies' and capital market participants' perceptions of relevant information. The disclosure agenda of companies is shaped by the perception of how capital market participants interpret valuerelevant information (Holland, 2004). A better understanding of how analysts processes this information is likely to affect firms' decision making in respect to ICI disclosure, potentially leading to a reduction in the information asymmetry in the market in relation to ICI.

In spite of prior research evidence that ICI is important to investors (Brown et al., 2014, García-Meca and Martínez, 2007, Orens and Lybaert, 2007, Sakakibara et al., 2010) and that some of its attributes are value-relevant (Ashton, 2005, Wyatt, 2008, Abhayawansa and Guthrie, 2010), prior literature offers little insight into the role of IC in the actual process of valuation analysis. The few studies that exist, whilst providing some insights in to investors' use of ICI in valuation, only focus on fund managers and buy-side analysts (Holland, 2003, Holland and Johanson, 2003, Holland, 2004, Holland, 2006). Hence, little is yet known and understood about the rationales and mechanisms of sell-side analysts' use of ICI in the process of company fundamental analysis, stock valuation and investment recommendation decision making, and factors influencing this usage. We focus on sell-side analysts because among the capital market actors, sell-side analysts are considered to be the most informed and sophisticated users of corporate information (Day, 1986, Schipper, 1991, Bence et al., 1995) who play a central role in providing investment and valuation advice to the market (Campbell and Slack, 2008). Other capital market participants such as fund managers and buy-side analysts rely on company research produced by sell-side analysts (Core, 2001, Fogarty and Rogers, 2005, Galanti, 2006) and are sometimes actively discouraged by their employers to go against sell-side analysts' advice when making portfolio selection decisions (Campbell and Slack, 2008).

This study is based on semi-structured interviews with sell-side analysts in Australia. Australia provides a good setting in which to examine the significance of IC in analysts' valuations. Over the past several decades new and innovative industries in bio-technology, financial and insurance services, software development, and the education sectors have 
significantly increased their share of GDP in Australia (Society for Knowledge Economics [SKE], 2007). As competitive advantage in these "new economy" industries is primarily achieved through the development and application of IC, the methodologies used by Australian analysts in identifying and incorporating ICI in their decision-making process when valuing such firms is of paramount importance to investors, policy-makers and researchers. An Australian study is also justified in light of research evidence that the extent of availability, perceived demand and analysts use of non-financial information differ by country (Olbert, 1994, Adhikari et al., 1998, Robb et al., 2001).

The paper contributes to the literature in the following ways. First we add to the valuation literature by explaining how IC is considered in the most fundamental judgements made by analysts when arriving at company valuations and investment recommendations. Prior research on the importance of ICI to stock valuation focused on identifying the impact of a limited number of quantifiable elements of IC on share prices or returns by using an empirical accounting research design. Whilst such a research design helps to discover statistical associations/links between measurable elements of IC and measures of value, it does not offer insight into the rationales and mechanisms of analysts' use of ICI. We believe 'how' IC is used is a more important question from an IC valuation perspective, than 'what' IC is used. We find that ICI alters valuation models' parameters, price targets and investment recommendations to reflect subjective assessments of risk, growth, earnings/cash flow forecasts and relative performance against peers. In order to understand IC valuation prior research has taken predominantly an asset-based valuation approach and focused on valuing IC separately (Flöstrand, 2006). Whilst such a focus satisfies the purposes of corporate reporting and asset management, it falls short on explaining the means by which IC is used in equity valuation (Penman, 2012). Our study differs from this strand of research as we adopt a whole of company perspective to understanding IC valuation.

Second, we add to the literature on analyst decision making. Our findings pertaining to the mechanisms and the rationale of analysts' use of ICI clarify sell-side analysts' notions of 'usefulness' of information. In this regard, we extend to sell-side analysts Barker et al. (2012) theorisation of 'useful' information in relation to fund managers. Barker et al. (2012) demonstrate that the actual investment decision process of fund managers differs from that assumed by neoclassical economic theory, and that there exists information that is not 'valuerelevant' or 'price-sensitive', but is still 'useful' and 'important' for fund managers. We report similar evidence in relation to sell-side analysts' perception of ICI, i.e., analysts regard 
ICI to be very 'important'/'useful' even when it is not perceived to be 'value-relevant'. This has important corporate disclosure and policy implications.

Third, we extend the research on factors influencing analysts use of ICI by finding that in addition to company and analyst specific factors identified by prior research (Flöstrand and Ström, 2006, García-Meca and Martínez, 2007, Orens and Lybaert, 2010) the mechanisms and the rationale of analysts' use of ICI is affected by the attributes of the context of analyst decision making and analysts' cognitive and time limitations. The qualitative methodological orientation of this study as opposed to the quantitative orientation of prior research has enabled rich insights on these influences on analysts' use of ICI in company valuation and stock recommendation decisions to be investigated.

\section{Theoretical framework and related research}

\subsection{Intellectual capital and valuation: background}

The process of sell-side analysts' valuation of companies involves various steps including information gathering, analysis of the company's business, performance and value drivers, forecasting of value drivers and valuation model inputs, selection and application of appropriate valuation methods to determine the intrinsic value and/or price target, and provision of an investment recommendation (Palepu et al., 2013). Analysts provide three major verifiable predictions: an earnings forecast, a target price and an investment recommendation (Asquith et al., 2005, Demirakos et al., 2010). Estimation of the intrinsic value or price target is the focal point of their analysis, as it informs the investment recommendation decision. ${ }^{1}$ Success at this task hinges on, inter alia, analysts' sound understanding of the company's value creation process, their ability to gather and convert relevant information into forecasts of value drivers (inputs into valuation models), and the selection and operationalisation of the most appropriate valuation model(s).

Prior research, based on surveys and interviews of buy- and sell-side analysts, demonstrates that analysts consider non-financial ICI to be useful and important for their analysis of companies and investment decisions (Brown et al., 2014, Dempsey and Gatti, 1997, Orens and Lybaert, 2007, Sakakibara et al., 2010). The non-trivial role of ICI is also documented in studies which examine references to this information in analyst research reports (Previts et al., 1994, García-Meca and Martínez, 2007, Abhayawansa and Guthrie, 2014), and in verbal

\footnotetext{
${ }^{1}$ However, occasionally analysts may devise price targets to justify ex-post their preconceived investment recommendations (Bradshaw, 2002).
} 
protocol studies which ask analysts to "think aloud" when analysing a company (Anderson, 1988, Coram et al., 2011).

It has been argued that the relative importance of types of information is temporal and contextual, and depends on the particular decision facing the analyst at a given moment. Bouwman et al. (1987) find that the importance of non-financial information increases when buy-side analysts transit from a familiarisation stage (i.e., where they familiarise themselves with the company) to an evaluation stage, and it peaks when summarising, analysing and integrating all acquired information. Coram et al. (2011) show that the attention analysts place on non-financial information is asymmetric depending on the trend-direction of the financial information available to them. Barker and Imam (2008) find that sell-side analysts' assessment of the quality and forecastability of such key inputs to valuation models as earnings is, to a large extent, driven by non-accounting (e.g., management quality, corporate strategy) information, which is used to contextualise and add meaning to accounting data. More generally, Mouritsen (2003) and Nielsen (2008) argue that the capital market's appreciation of IC is fragile and there is a general ambivalence to certain types of ICI.

This literature, however, stops short of exploring analysts' actual use of ICI in their analysis and forecasting of value drivers (i.e., inputs to valuation models), derivation and justification of intrinsic value estimates and price targets inferred from the employed valuation models, and investment recommendation decisions. The value-relevance literature provides ample, though indirect, evidence that various elements of IC are reflected in analysts' price targets and investment recommendations. ${ }^{2}$ Analyst survey-based research ranks certain types of ICI as the most important inputs to both analysts' earnings forecasts and investment recommendations (Brown et al., 2014). Similarly, content analytic research of sell-side reports uncovers statistical associations between recommendation types and references to such elements of ICI as company management and strategy (Breton and Taffler, 2001). Nevertheless, one can still describe as a 'black box' the actual mechanism of analysts' use of ICI in generating forecasts and valuation model inputs, deriving stocks' intrinsic values or price targets, or deciding on investment recommendations. It is the objective of this study to

\footnotetext{
${ }^{2}$ Further indirect evidence of investors' use of ICI is reported in value-relevance studies which document positive association between various IC indicators (e.g., R\&D, software development costs, brand equity, patents, customer satisfaction and loyalty, organisational capital) and share price (see Abhayawansa and Guthrie, 2010 for a review of this literature).
} 
penetrate this black box and offer further insight into how analysts' actually utilise this information. Below, we develop a conceptual framework of analysts' usage of ICI and discuss relevant theories and empirical literature that support the elements of the framework.

\subsection{A conceptual framework of analysts' use of intellectual capital information}

According to our conceptual framework (Figure 1), ICI has six functions in analysts' valuation and investment decision process. The first function of IC (arrow 1) is to help analysts form an overall opinion about the company and contextualise the company's business and value creation story. Past the opinion forming stage, the analyst can utilise ICI in forecasting and valuation tasks. More specifically, IC might be a factor considered in the selection, rationalisation and application of an appropriate valuation model (arrow 3), and/or it may enter a valuation model indirectly, by affecting the model's inputs (arrow 2). Our conceptual framework also allows for the possibility that the price target (or intrinsic value) does not flow directly from a model-derived valuation, but is moderated in light of ICI (arrow 4). Further, ICI is envisaged as having the potential to serve as a subtext for the investment recommendation or even amend it (arrow 5). Finally, ICI can be used to reinforce, clarify and extend the message/advice that the analyst wishes to convey to clients in private communication (arrow 6). Sections that follow discuss each of these functions of IC in more detail.

\section{$<$ Insert Figure 1 about here $>$}

\subsubsection{Intellectual capital and opinion forming}

ICI may be part of the analysts' opinion forming process (or understanding) about the company which feeds indirectly into valuations and also underpins the opinions conveyed in discussions with clients (arrow 1). It can also be used as background information about the company in an analyst report where the impact of changes in the industry and the business environment is explained. Holland (2004) argues that buy-side analysts construct a 'mosaic' of corporate value creation and performance by accumulating pieces of information about the company. The information forming the mosaic is seen as transient, narrowly conceived and insignificant in isolation but meaningful within the mosaic (Holland and Johanson, 2003). It is shown that the mosaic provides a coherent means to combine ICI with other fragmented information to construct a broader picture of the company (Holland, 2006). 


\subsubsection{Valuation models and intellectual capital as inputs}

Valuation models can be classified into two types: sophisticated or fundamental models, that require extensive forecasting of value drivers and application of discounting (e.g., discounted cash flow [DCF] model, residual income valuation [RIV] model, dividend discount model $[\mathrm{DDM}]$, etc.), and less sophisticated comparables-based valuation techniques (e.g., price-toearnings $[\mathrm{P} / \mathrm{E}]$, enterprise value-to-earnings before interest, tax, depreciation and amortisation [EV/EBITDA], price-to-free cash flow [P/FCF], dividend yield [DY], etc.). Valuation models can also be classified as cash flow based (e.g., DCF, DDM, P/FCF, DY, etc.), and accrual based (e.g., RIV, P/E, EV/EBITDA). Prior research into sell-side analysts' use of valuation models shows that analysts may rely on one model, combine different models in sum-of-theparts (SOTP) valuation, or use two or more models in a complementary manner (Barker, 1999, Bradshaw, 2002, Demirakos et al., 2004, Asquith et al., 2005, Imam et al., 2008, Imam et al., 2013).

The fundamental valuation models (DCF, DDM, RIV) estimate the intrinsic value as the present value of future payoffs (free cash flows, dividends, residual earnings), where the forecasted future payoffs are discounted at an appropriate discount rate (cost of capital). While these models are formulaic, their inputs (forecasts of payoffs, cost of capital, etc.) need to be generated by analysts, and there is no universal approach for doing this. In fact, analysts have to exercise their own judgement and discretion when generating these inputs (Penman, 2012, Palepu et al., 2013).

The comparables-based valuation method infers value from the observed value of comparable firms (or other benchmarks). This method is based on the concept of the law of one price, whereby two similar assets should trade at similar prices (and price multiples). The method estimates the firm's value by applying the peers' average multiple (e.g., P/E) to the firm's corresponding measure of value creation (e.g., earnings). It uses minimal information and often does not require forecasting of inputs.

Theoretical and empirical accounting literature suggests conceptual and empirical superiority of RIV over other models (Penman and Sougiannis, 1998, Francis et al., 2000, Jiang and Lee, 2005). RIV is the only model where value created by intangible assets (and IC) is reflected in its theoretical rationalisation. Penman (2009) demonstrates that RIV enables the value of intangible assets, which are omitted from the balance sheet, to be ascertained from the 
income statement (i.e., the reported earnings) and reflected in valuation. ${ }^{3}$ RIV expresses the equity value of the firm as the sum of equity book value and the present value of the future expected residual earnings. The value implied in unrecognised intangible assets and, more generally, IC is captured in the residual earnings term of the model. Penman (2009) applies a simplified version of RIV to two intangible asset intensive firms, Microsoft and Dell, to demonstrate that RIV can produce a fairly accurate valuation even when much of the firms' intangible assets are missing in the balance sheet. ${ }^{4}$

Paradoxically, RIV does not feature among the models commonly used by analysts, despite the evidence that investors consider ICI useful in their investment decisions (e.g., Holland, 2004, Barker et al., 2012), and that elements of IC are associated with stock prices (Ballester et al., 2003, Lev et al., 2009, Livne et al., 2011). It is not RIV, but DCF and PE (or EV/EBITDA) which are in most common use among sell-side analysts (Brown et al., 2014, Demirakos et al., 2004, Imam et al., 2008, Imam et al., 2013)5. Demirakos et al. (2004) report that RIV was used in only $2 \%$ of their sample of analyst reports, while DCF and PE were used in $38 \%$ and $85 \%$ of reports respectively. In making a model choice, analysts opt for models they are most familiar with, and consider the extent to which the published accounting information can be used as a credible starting point for the analysis (Demirakos et al., 2004). Their use of models is also influenced by clients' preferences, i.e. analysts opt for models that their clients expect them to use or that are currently 'fashionable'(Imam et al., 2008). However, there is lack of evidence as to why RIV is not commonly used.

\footnotetext{
3 RIV is derived from the classical dividend discount model by replacing the dividends with their accounting articulation under the assumption of 'clean-surplus' accounting (Peasnell, 1982, Ohlson, 1995). The 'cleansurplus' accounting assumes that no item affects the book value of equity directly, bypassing the income statement, i.e.: $B V_{t+1}=B V_{t}+$ Earnings $_{t+1}-d_{t+l}$. Where $B V$ is the book value of equity, and $d$ is dividends. Substituting $d_{t+1}=$ Earnings $_{t+1}-\left(B V_{t+1}-B V_{t}\right)$ into the classical dividend discount model produces the residual income valuation model in its general form: Value $_{t}=B V_{t}+\sum_{\tau=1}^{\infty} \frac{\text { Earnings }_{t+\tau}-r B V_{t+\tau-1}}{(1+r)^{\tau}}$, where $\left[\right.$ Earnings $_{t+\tau}-$ $\left.r B V_{t+\tau-1}\right]$ is the residual earnings for the forecast year $\tau$.

${ }^{4}$ Importantly, however, residual earnings will correctly account for the value created by off-balance-sheet intangibles only if the firm is in steady state (i.e., there is no growth in intangible assets).

${ }^{5}$ The rationale for analysts' valuation model preferences is not yet well understood (Ohlson, 1995, Imam et al., 2008, Imam et al., 2013), but such decisions may reflect analysts' individual preferences (Lundholm and Sloan, 2004) and the influence of institutional investors (Imam et al., 2008).
} 
It is envisaged that, because most valuation models do not explicitly allow for 'soft' ICI, this information (if used by analysts) can enter formal valuation through valuation models' inputs. Indeed, Holland (2004) notes that analysts utilise qualitative ICI (e.g., management quality) to adapt various valuation model inputs such as forecasts of cash flows and earnings, and peer-based valuation multiples, and Barker (1999) reports that analysts use their perceptions of the target company's management quality to adjust their estimates of the terminal value element in their fundamental valuation models. Indirect evidence of the impact of IC on valuation models' inputs is documented in empirical accounting literature. Specific elements of ICI (e.g., network advantages, patent citation, corporate performance quality, subscriber base, market share) are found to be statistically associated with analysts' earnings and revenue forecasts (Rajgopal et al., 2003, Thomas, 2003), and earnings and revenues reported by companies in subsequent periods (Lev and Sougiannis, 1996, Nagar and Rajan, 2001). Prior studies also demonstrate that disclosure of ICI can lower companies' cost of capital (and, hence, the discount rate) through reduction of information asymmetry and of information risk (Vanstraelen et al., 2003, Mangena et al., 2010). It should be emphasised, however, that while this empirical accounting literature reveals the phenomenon in question (i.e. potential impact of ICI on valuation model inputs), it cannot provide insight into how analysts actually use ICI when estimating/forecasting the payoffs, discount rates and other valuation model inputs.

\subsubsection{Intellectual capital and price target setting}

Our framework setting out analysts' use of IC also allows for IC to be used as a qualitative overlay on the intrinsic value estimate derived by analysts (arrow 4 in Figure 1). It is conceivable that analysts may be unable (or choose not) to incorporate ICI formally in valuation through input variables. Instead, they may choose to moderate the valuation models' output in a direction suggested by their 'soft' IC-type information, i.e., apply a premium or discount to their models' value estimate. This function of IC echoes Barker et al. (2012) findings that ICI (in particular, structure and management of the business, corporate strategy and other IC determinants of business performance) plays the role of confirming, or throwing doubt upon, the information and assumptions used in fund managers' valuation models. Thus ICI may have confirmatory value at the price target determination stage.

\subsubsection{Intellectual capital and investment recommendation}


IC may enter an analyst's decision making process at the investment recommendation stage, to justify or even modify an investment recommendation direction implied by the intrinsic/target value estimate (arrow 5 in Figure 1). Bouwman et al. (1987) observe that investors use quantitative financial information primarily to screen for early rejection of unacceptable investments, while the final decision to invest is based, to a large degree, on qualitative nonfinancial information. Prior research indicates that investment recommendations do not always flow directly from valuations. For example, Bradshaw (2004) reports that analysts' earnings forecasts, when incorporated into cash flow based models, provide valuations inconsistent with their stock recommendations, indicating that recommendations also incorporate other (nonfinancial) information. The extent of ICI usage in analysts' justifications of recommendations (and, more generally, in analysts' reports) is found to be related to the recommendation type (Ho and Harris, 2000, Breton and Taffler, 2001, Bradshaw, 2002). Furthermore, García-Meca and Martínez (2007) argue that IC usage and investment recommendations are endogenously related, i.e., recommendations may lead analysts to consider ICI to justify them and, at the same time, ICI may drive the recommendations.

\subsubsection{Intellectual capital and client communication}

Analysts' communications with clients include more information than earnings forecasts, price targets and investment recommendations. Their reports to clients include narrative information exemplifying the appropriateness and basis of their assumptions, judgements, forecasts and the recommendation (Previts et al., 1994, Nielsen, 2008). Bradshaw (2002) and Ho and Harris (2000) find that analysts are selective and strategic in their use of financial and non-financial information in their reports. Research evidence suggests that investors recognise the importance of narrative information in analyst reports. The market reacts to the strength and quality of arguments and the tone and level of detail in analyst reports (Hirst et al., 1995, Asquith et al., 2005, Twedt and Rees, 2012). Among the narratives in analyst reports are information about company IC and other types of non-financial information (Flöstrand and Ström, 2006, García-Meca and Martínez, 2007, Orens and Lybaert, 2007, Abhayawansa and Guthrie, 2014). It is found that ICI is used strategically by analysts in their reports to manage perceptions (Abhayawansa and Guthrie, 2012) among other things. In this light analyst reports can be viewed as a communication medium through which analysts attempt to push their agenda for the company and ICI may play a role in achieving this objective. 
Arguably, an even more appropriate mechanism for disseminating non-quantitative information is analyst-client meetings due to the privacy and instantaneity they provide. However, we are yet to scientifically understand the types and extent of information disseminated through analyst-client meetings due to the lack of research on the role of such meetings. Nonetheless, it is envisaged that ICI would play at least some role in meetings between analysts and clients.

\section{Method}

Valuations and recommendations are largely affected by analysts' perspectives of the company which have been built over a long period of time (Barker et al., 2012). Hence, investigation of analysts' use of ICI requires these perspectives to be analysed and the formation of them to be understood. The formation of analysts' perspectives cannot be empirically observed through participant observation methods nor can the analysts be asked to verbalise their thought processes pertaining to their formation in a controlled setting. The semi-structured interview has the distinct advantage of enabling the exploration of past decisions and general behaviour reflected in everyday decisions without imposing temporal boundaries. Compared to more structured methods, semi-structured interviews can generate rich descriptions of phenomena that have not been well understood and provide insight into new research fields (Barker, 1998, Holland, 2006), such as the one we investigate. As the researcher cannot be expected to know in advance all necessary interview questions needed to fully explore analysts' perspectives, the flexibility of the semi-structured interview offers an advantage over other research methods (Diefenbach, 2009). In an under-researched area there are not many hypotheses one could formulate and test. In this regard the usefulness of a semi-structured approach lies in its ability to allow hypotheses that might not have been apparent in advance to emerge from and within the data (Barker et al., 2012).

This research method gives us the flexibility to customise the interview by modifying the style, pace and ordering of questions based on the circumstances of the interview, the background of the interviewees and their flow of thoughts, and to fully explore emerging themes that were not originally anticipated (Qu and Dumay, 2011). Further, it allows the interviewer to intervene to tease out aspects important to the study and seek clarifications and elaborate explanations by way of supplementary questions. The broadness of the questions, which is typical of the semi-structured method of interviewing, enabled us to explore the use of ICI from the analysts' perspective rather than from the researchers' perspective. Although not to the same extent as participant observation or ethnography, we could still delve into the 
life world of the analysts by engaging with their experiences and understanding and interpreting the phenomenon from within the life world of these skilled professionals $(\mathrm{Qu}$ and Dumay, 2011, Barker et al., 2012).

Semi-structured interviews have proved to be successful in prior research involving investment professionals in investigating phenomena such as use of accounting information (Barker, 2001), usefulness of company-fund manager meetings (Barker et al., 2012), value and relevance of narrative reporting (Campbell and Slack, 2008) and decision usefulness of annual report environmental narratives (Campbell and Slack, 2011).

As the first step in sample selection we obtained a list of all full-service brokerage firms from the website of the Australian Securities Exchange. The list included 36 analyst firms operating in Australia. Then a list of analysts working for those brokerages and their contact information was compiled from publicly available information gleaned from brokerage firm websites and analyst reports. A total of 90 analysts from 20 firms were identified in this way. The identified analysts covered 19 industries of the Australian economy. Analysts on the list were contacted by telephone to determine their interest in taking part in the study. Those who expressed an interest were then provided with a formal invitation. The invitation set out the objectives of the research, the parameters governing the use of the data collected and the procedure for conducting the interview in accordance with the university ethics clearance conditions. It was explicitly stated that all information provided would be kept confidential and respondents would not be identified. An interviewer guide with open-ended questions was used to frame the interview and ensure that issues important for this study were raised in the event the respondent failed to address them naturally in the course of the interview. The first interview was treated as a pilot interview and several changes were made to the interviewer guide based on experience gained from it. This interview was not used in the analysis. The next few interviews also triggered minor changes to the interviewer guide as a result of new questions emerging during and because of the investigation. Diefenbach (2009, p.877) posits such changes enable "an increasingly better and deeper knowledge and understanding of the objects of reasoning and recognition of emerging patterns". However, the additional questions were only of peripheral importance. The main questions did not change throughout the interviews.

The first interview question directed to all the respondents was "have you heard of the term intellectual capital and how would you explain it". Upon obtaining a detail response to this 
question the respondents were provided with the following conceptualisation of IC which is adopt in this paper ${ }^{6}$.

Intellectual capital can be explained as intangible determinants of firm value. They are resources with a non-physical existence having the potential to generate future economic benefits. Intellectual capital can be categorised into three groups: human capital, structural capital and relational capital.

We also defined human, structural and relational capital based on MERITUM (2002) and examples were provided for clarity of understanding. In order to avoid the impression that the interviewers were judging interviewees on their understanding of IC and its components we emphasised to them that there is no universally agreed and accepted definition of IC, and that the definitions that were provided are the ones that tend to be the most commonly used in academic research. The interviewees were instructed to adopt these conceptualisations of IC and its constructs during the course of the interview. Further clarifications were provided when necessary. We then posed the broad question of how ICI is used in the analyst' work relating to company valuation with instructions to talk freely on this broad topic. This enabled us to elicit detailed, in-depth responses. Analysts were prompted to reflect on their past and present experiences and provide actual examples to corroborate their views (without disclosing sensitive/proprietary information). This ensured that analysts' discourse was of reflective rather than of normative nature. Using the interviewer guide the interviewers made an attempt to ensure that the following were covered in each interview.

- Use of ICI in valuation models and in estimating valuation parameters

- How ICI affects derivation of intrinsic values, price targets and investment recommendations

- Impact of ICI on risk assessment

- Role of structural, relational and human capital in firm valuation and the link between IC and management quality

- Factors affecting the use of ICI in company analysis (e.g., company size, sector, clients' needs)

\footnotetext{
${ }^{6}$ This conceptualisation of IC was formed based on a thorough review of the IC literature and professional pronouncements on IC measurement and reporting.
} 
- How information about IC that the analyst has gathered is communicated to clients

- Analysts' sources of ICI and the relative importance of the sources

The questions in the interviewer guide were adjusted in accordance with the flow of the interview and it was not necessary to bring up all the questions in every interview. Follow-up questions were asked and probing techniques were used where respondents did not sufficiently elaborate their responses or introduced issues not originally captured by the interviewer guide but were of potential importance. On average, the duration of each interview was approximately 40 minutes.

A total of 19 interviews were conducted with analysts in 2011. We did not ex-ante specify a limit on the number of interviews as statistical validity does not drive sampling in qualitative research. Rather, the sample size should be driven by the need to fully capture the depth and breadth of the phenomena. Data analysis was undertaken concurrently with data collection, enabling us to determine the extent of incremental insights generated by each interview. Data saturation was starting to occur with the $17^{\text {th }}$ interview signalling that data collection is complete (Kuzel, 1999). Lye et al. (2005) explains "data saturation occurs when new data that are collected fit the categories already derived from prior analysis, are repetitive, and no new themes emerge". Two further interviews were conducted then, taking the total number of interviews to 19 , to ensure that our judgement of data saturation was reasonable. Our sample size compares favourably with prior research involving investment professionals, especially sell-side analysts, providing additional assurance of the adequacy of the sample size (Campbell and Slack, 2008, Campbell and Slack, 2011, Barker et al., 2012). As one cannot completely avoid the possibility of the next interview bringing in different insights than the previous ones, we identify restricting the interviews to 19 as a limitation of our study.

The analysts covered large-, small- and micro-cap companies operating in a number of industries (see, Table 1). Whilst the industries reported in the table are the ones that are currently covered by the analysts it was revealed during the course of the interviews that the analysts have covered other industries in their previous roles. Experience gained in their previous roles covering these other industries was drawn upon in responding to interview questions. However, the fact that not all industries were covered by the analysts can be identified as a potential limitation in so far as the rationales and mechanisms of analysts' use of ICI differ between the industries that are covered and not covered. Nine brokerage firms were represented in the sample. Three are international firms with extensive international 
networks and six are primarily Australian operations. The brokerage firms varied from small local boutique firms with less than six analysts to large international firms with more than 300 analysts working in offices located in many countries and regions. Of the analysts interviewed 9 had 5 or less and 4 had between 5 and 10 years of work experience as an analyst. Five analysts had more than 10 years of experience.

Table 1: Details of Interviewees

\begin{tabular}{lllll}
\hline Analyst & Sector/industry focus & $\begin{array}{l}\text { Experience as } \\
\text { an analyst }\end{array}$ & $\begin{array}{l}\text { Size of analyst } \\
\text { firm }\end{array}$ & $\begin{array}{l}\text { Firm's } \\
\text { operations }\end{array}$ \\
\hline $\mathrm{A}$ & Consumer goods & 7 years & Large & International \\
$\mathrm{B}$ & Materials (Mining) & 9 years & Large & Local \\
$\mathrm{C}$ & Industrial/Emerging growth/Small-cap & 6 years & Medium & International \\
$\mathrm{D}$ & Consulting Services/Small- & 11 years & Large & International \\
& cap/Emerging growth & & & Local \\
$\mathrm{E}$ & Industrial /Micro-cap & 11 years & Large & Local \\
$\mathrm{F}$ & Retail (Beverages) & 5 years & Medium & Local \\
$\mathrm{G}$ & Industrial (Oil \& Gas) & 2 years & Small & Local \\
$\mathrm{H}$ & Industrial & 4 years & Large & Local \\
$\mathrm{I}$ & Industrial/Business services/ Small cap & 5 years & Small (Boutique) & Local \\
$\mathrm{J}$ & Financials & 5 years & Medium & International \\
$\mathrm{K}$ & Financial (Insurance) & 5 years & Large & International \\
$\mathrm{L}$ & Industrial (Chemicals/material) & 11 years & Large & International \\
$\mathrm{M}$ & Healthcare (Biotech) & 7 years & Large & Local \\
$\mathrm{N}$ & Industrial/Small-mid cap & 5 years & Small (Boutique) & International \\
$\mathrm{O}$ & Transport (Airlines) & 12 years & Large & International \\
$\mathrm{P}$ & Telecommunication & 4 years & Large & International \\
$\mathrm{Q}$ & Industrial (Building products)/ & 5 years & Large & International \\
$\mathrm{R}$ & Emerging growth & & & Local \\
\hline
\end{tabular}

The interviews were audio recorded with the permission of the respondents. The audio recordings were then transcribed and checked for accuracy. The transcripts were imported into Nvivo, which is software designed to facilitate qualitative research, for ease of analysis and for organising content into themes. First, a node structure was created in Nvivo reflecting the IC flows identified in our conceptual framework (Figure 1) in order to collect and organise responses. The nodes represent the main themes pertaining to the decisions analysts make in valuing companies and advising clients. Next, we analysed each node, which displayed all the responses on the particular information flow, for common or recurring themes within it. Second-level nodes were created within the main nodes for each theme resulting in a tree node structure. Cases were coded into these second-level nodes. Also, new first-level nodes were created when a new use of ICI which was not represented within the existing nodes matrix emerged as a theme. 
The node structure represents the thematic conceptual matrix described by Miles and Huberman (1994, p.10) which enables "selecting, focusing, simplifying, abstracting, and transforming the data". The nodes enabled similar responses to be isolated and carefully examined for further subtle differences and they acted as a repository of quotes for use for illustrative purposes in the paper. We created memos to document the variations observed within nodes and to identify recurring themes. Nvivo enables the memos to be easily traced back to the thematic nodes and cases. Although our analysis is predominantly a variableoriented one with the focus on comparing and contrasting themes, the analytical features of Nvivo enabled a case-oriented analysis (with a focus on individual interviewees' characteristics) providing richer insights into the investigated phenomena. This dual analysis balances particularistic orientation in the case-oriented analysis with the generalistic features of the variable-oriented analysis (Clatworthy and Jones, 2008).

\section{Findings}

Our analysis of the interview data revealed 5 themes which correspond closely to the ICI flows identified in our conceptual framework (see figure 1). These include (1) formation of perception of the company; (2) determination of inputs to valuations; (3) determination of the target price; (4) justification of the investment recommendation; and (5) client value addition. In this section, these themes are used to discuss the mechanisms and rationales by which ICI is incorporated in analysts' decisions making.

\subsection{Formation of perception of the company}

Gathering information that enables analysts to understand the company and its value drivers within the context in which it operates is the first step in company valuation. Bouwman et al. (1987) identified a similar stage, which they referred to as the 'familiarisation stage', in buyside analysts' decision making process. All but one analyst indicated that they purposefully seek ICI to understand the company. In generating this understanding analysts not only sought information on critical intangible value drivers and sources of competitive advantage but a broader set of IC and its interactions. ICI also enabled analysts to generate questions for company management and responses to these questions were used to better understand the company.

There's got to be good reasons for everything and it (i.e., ICI) is a good basis or a starting point for asking questions about the company at whatever weekly or monthly meetings you have with them. (Analyst A - Consumer goods) 
The knowledge of IC value drivers of the company enabled analysts to build credibility with fellow analysts and clients by showcasing their in-depth understanding of the company.

Analysts understood human capital as the quality and credibility of the management team. In industries such as biotechnology and wealth management, key employees (e.g. fund managers, pathologists etc.) were included in analysts' definition of human capital. Structural capital such as policies, communication channels, organisational structure, internal processes and strategies provided an understanding of the internal functioning of the firm and the extent to which the firm operated in a disciplined manner. Other structural capital elements, such as information systems and technology were seen as enabling the firm to maintain its status quo and derive value in the medium term. On the relational capital side, customers and suppliers received the most analyst attention with relationships with regulators having relevance in specific industries, such as telecommunications. However, relational capital received significantly less attention compared to human and structural capital. All analysts concurred that human capital is the most important IC category or as equally important as other IC categories.

I go through each of these three categories [of IC] in initial due diligence.... I look at all three. Perhaps more so the human capital. For some of the other companies structural would be more important. The third one (i.e. relational capital) is relevant to an extent, but out of the three the first two would be more relevant for me. (Analyst J - Financials)

Analysts appear to discriminate between the notion of understanding the company and forming a view (or a judgment) about it. The latter involves a value judgment as to the company's quality and strengths, while the former was not value laden. Once analysts understood the company, they moved on to forming a view about it. This view is based on their perception of the quality and strengths of a particular company, formed to a large extent by giving consideration to ICI. However, their perception of management quality shaped analysts' overall view of the company (this was the case for 18 analysts). Three analysts commented that they would not continue covering a company if they were not comfortable with the management quality. Perception of management quality is treated as a proxy for other aspects of a company's IC, because the efficacy of relational and structural capital depends on management quality.

Within the mining space you obviously need a management base that has the ability to structure financing arrangements to build mines and obviously have the capacity to find large clients or similar. ... you need [to have] confidence that the management has the ability to beat the rest, I 
suppose, put in systems and processes and obviously have the right product at the right point in time. (Analyst $\mathrm{H}$ - industrial)

You can have all the safety procedures on the planet but if you've got cultural issues and you don't have good people running it, you will always have safety problems. (Analyst L industrial)

The quality of management thus becomes a screen through which the company is perceived as good or bad. When assessing the quality of management, analysts used a two pronged approach. First, the analysts' assessment of the quality of management depends on their perception of the management team. The past performance or the track record of senior management, their commercial know-how and understanding of the markets, strategy and value drivers were considered important in this assessment. Analysts also sought the views of fund managers and institutional and retail clients on the management of the company.

Second, ICI becomes a proxy for quality of management. Management quality is judged with reference to the company's success in building relational (e.g. supplier and customer satisfaction), structural (e.g., systems and processes) and human capital (e.g., employees satisfaction). When judging the quality of IC, analysts relied less on managements' commentary of IC and ICI published in annual reports due to potential bias in such communications. Instead, analysts obtained ICI first hand through site visits, experiencing company's products and services from the perspective of a customer and by talking to customers, suppliers, business partners and (ex-)employees.

The degree of reliance placed on the quality of management and/or ICI in building a view of the company depended on the type of industry and company size (15 analysts). Analysts considered the quality of management to be very important for firms in knowledge and technology-intensive industries (e.g., technology, biotechnology and healthcare) and competitive industries, and less important for firms in traditional or less competitive industries (e.g., mining, commodities, manufacturing and transport). There are inter- and intra-industry differences in the importance of different types of IC in building a view of the company. Even in an industry like commodities, which is heavily physical capital intensive, analysts saw certain aspects of IC to be more important in this regard.

It does get a little bit less important in something like commodities. ... But there are still [...] quite a number of differences around the corporate structures, the hierarchy and in the processes that businesses have in place. They all operate from different points on the cost curve 
and some of that will be a function of the systems and processes they have chosen to put in place. [...] and that will have an impact. [Analyst $\mathrm{O}-$ transport]

Seventeen analysts stressed that ICI is more important for smaller companies when forming a view of the company. The size effect was attributed to key person risk, as the success of smaller companies is more closely associated with a good management team, its vision and procedures.

In the analysis the smaller the market cap of the company the more important the qualitative factors are because they will have a much larger impact on the overall quantitative results over time. Within the really big companies [...] the structural capital and the IT stuff as well, are well and truly locked in, and the qualitative factors of the human capital make a bit of a difference at the margin, whereas in small companies it makes a huge difference. And in most cases you will make an initial sort of go or no go call on the company based upon the human capital before you actually do anything else. (Analyst L - Industrial)

The analyst's view of the firm served several purposes. First and at a fundamental level it informed the analyst's decision whether to cover a particular company. Second, it influenced the level of confidence placed on the information provided by the management and the management's ability to execute announced strategy. Finally, analysts formed an overall perception of the future prospects of the company and evaluated the company relative to its peers based on the view of the firm. Eleven analysts acknowledged that their view of the firm implicitly seeps into valuation via these avenues. As discussed later in this section an analyst's view of the firm also seeps into the ultimate stock recommendation issued for the company and it is conveyed to clients in discussions. Analysts were unanimous on the fact that their view of the firm, informed by their assessment of the firm's IC, underpins the valuation process.

\subsection{Determination of inputs to valuations}

All but one analyst interviewed in this study used the DCF model. Price multiples based models were commonly used (16 analysts), but mostly as subsidiary models. Some analysts also used SOTP or blended valuation models with DCF and PE as variants within them. Most analysts used more than one model, with the DCF (as the main model) and PE combination being the most popular. Imam et al. (2008) provide similar evidence.

Our analysis revealed that despite the unquantifiable and uncertain nature of the information the majority of the analysts (17 analysts) directly used ICI in one or more of their valuation models. ICI was used to adjust the models' input variables and to moderate/adjust the final 
valuation. Importantly, analysts were in agreement about the fact that they used their judgement and experience to translate the qualitative ICI into quantitative terms, and that they had no explicit or deterministic techniques for doing so.

The reminder of this section discusses how ICI is utilised by analysts as inputs in DCF-based and multiples-based valuation models.

\subsubsection{Intellectual capital information and DCF model parameters}

Analysts' utilised ICI when estimating DCF valuation inputs such as cash flow/earnings (including growth rates and timing) and discount rates. The most common use of ICI in DCF models was in estimating forecast earnings/cash flows (14 analysts). Incorporating the impact of IC via the discount rate was an alternative to adjusting the original earnings/cash flow forecasts to account for ICI. The two approaches were often considered mutually exclusive as otherwise the impact of IC would be double counted within the target price. Both these approaches were less than scientific, and analysts drew heavily on their experience. The selection of either approach was largely a matter of analysts' individual preference and, importantly, depended on the intelligibility and quantifiability of ICI.

\subsubsection{Cash flow/earnings forecast}

Three clear approaches to determining the impact of ICI on forecast earnings can be identified. The first is to estimate the impact of IC on future sales and, as a result, forecast earnings/cash flows. In so doing, the impact of changes in human or structural capital was channelled through relational capital, or more specifically by assessing the impact on customer service levels and market share. The impact of a change in customer numbers on sales was easier for analysts to quantify.

$\mathrm{He}$ (the CEO of the company) was going to reduce 1400 systems down to whatever it was - a much smaller number and it would have an effect on costs. But it would also have an effect on simplifying the system, so they can be more responsive to customers and allow them to package and bundle more often. ...If you were cutting [the headcount] too heavily then, I guess, there is a potential that you start to lose some customer contact - customer relationship. (Analyst R - Telecommunication)

In the second approach, analysts determine how conservative or aggressive they could be with their forecasts and in moderating management's forecasts, based on their assessment of management quality, changes in management/strategy, and the management's past track record of meeting forecasts. A poor past track record by the company was considered to be a 
reflection of poor IC (particularly structural capital such as systems and processes) and management's inability to formulate strategy and leverage company IC in executing the strategy.

Clearly our confidence or lack of thereof, in the ability of [Company X] to deliver a stated 120 million synergies, whether or not we think that is conservative, does depend a lot on whether or not we give management the credibility to have the execution ability. (Analyst $\mathrm{K}$ - Financial)

A variant of this approach is adjusting the timing of earnings/cash flows in management's forecasts. Timing adjustments were made not due to analysts' doubting management's ability to achieve their forecasts but when it was believed that the timing of particular earnings/cash flows could be delayed due other factors, for example, management quality.

If a key person is leaving and typically [he/she is] the one with the relationships, [then] that doesn't necessarily change the outcome of the project or the discount rate. But it might push it out six or twelve months. That's how it can impact the valuation. ...Any delay will see the discounting setback. (Analyst B - Materials)

Third, IC was accounted for through assumptions about growth rates. The growth rates were based on analysts' assessment of the future outlook of the company, which in turn depended heavily on their perception of company IC. Relational capital such as brands and relationships with customers and stakeholders were considered to be more relevant than other IC in deciding the extent to which the company can maintain growth. Growth was estimated in light of competitive pressure, which was exemplified as a function of company relational capital. Both the changes in specific IC attributes, such as exceptional customer service, and analysts' perception of management quality were considered in adjusting the growth rates.

So forecasting, particularly, revenue and revenue growth and profitability growth is a function of your assessment of management and the soft stuff that will translate into those assessments....Well you would change the rate of growth depending on whether or not you think they have got the personnel to deliver. So it will feed into growth rates predominantly. If you are losing people that you know are bringing the sales in, you will slow your sales growth down. (Analyst L - industrial)

A minority of analysts, however, refrained from incorporating ICI in cash flow/earnings forecasts or other inputs to valuation models. Two of the three analysts who held this view argued that, and as pointed out by Penman (2009), the impact of companies' IC is already captured in the earnings reported in the income statement. These analysts saw IC as an 
overarching store of value in a company which is reflected through a company's sales process and profit margin.

I've seen analysts and investors think about or comment that certain stocks deserve a premium or deserve a discount because of lack of good systems or something like that, but to me that would be reflected in a lower profit margin or inferior performance which you can capture in cash flows. (Analyst $\mathrm{O}$ - transport)

Accordingly, the existence of IC is automatically acknowledged when a company's profit margin compares favourably with its peers' or its past profit margins. The analysts who held this view considered that earnings should be forecasted without special consideration of the impact of any IC, assuming future earnings are a direct function of current earnings.

Inability to quantify the impact of IC on valuation input parameters such as forecast earnings or cash flows was also highlighted by analysts in explaining their decision not to use ICI in their valuation. Their concern was the difficulty in justifying a valuation if the IC impact was subjectively quantified. Such an attempt could put their credibility within the analyst community and reputation with clients at risk.

For me to change my valuation or my earnings or my inputs into the DCF calculations, I need to have a firm view as to how much value does that individual add or a particular process add and that is really hard to do. My personal view is that in our roles in the industry you would be kidding yourself if you thought that you could actually define what that number is. So I look at it and say okay it doesn't change my view in terms of the actual numbers. (Analyst P Telecommunication)

Nonetheless, all analysts commented that ICI strongly influences their view of the company that may be reflected in the ultimate stock recommendation or discussion with clients.

\subsubsection{Discount rate}

About half the interviewed analysts indicated that they consider ICI when determining the discount rate. Those who did not adjust the discount rate for ICI explained that it was because they had already adjusted the numerator of the DCF model (i.e. cash flows/earnings) for such information or because they assumed that the impact of companies' IC is already captured in the earnings reported in the income statement.

The discount rate was determined by adjusting the equity risk premium by adding a premium or a discount to it based on their perception of company's IC. This was a highly judgmental 
process as the percentage discount or premium was determined based on the analysts' subjective assessment of the company's IC.

You wack them with the risk. So companies that have got a high level of intellectual [capital] be it systems, be it management experience - would, I guess, be a lower risk proposition than a company that had very little intellectual capital that was open to competitive forces. ...I could think of lots of examples where companies are operating in the same space, but one of them might have paper protection on one of their technologies or one of their applications, and they definitely trade at a premium. So, it's definitely taken on board, it just tends to be not quantitative, because it is very difficult to quantify. (Analyst D - Services)

The decision to adjust the discount rate rather than the earnings/cash flows forecast was attributed to the difficulty of quantifying the impact on earnings of status/changes in IC.

Companies that have strong brand and strong relationships with suppliers will tend to maintain their margins better than companies that don't have those. So, you can be explicit in your [earnings] forecasts. But the thing that is very hard to kind of model or forecast is the value that management experience and expertise brings. That tends to get reflected in the discount rate rather than in the earnings, so companies with rubbish management get penalised and companies with great management obviously get a benefit at the discount rate level. (Analyst D - Services)

The discount rate was not adjusted for temporary changes in company IC such as resignation of key managers. Such changes were captured in the market sentiment and dealt with by amending the 12-month price target instead (see next section). Only the aspects of IC, such as management quality, that would cause long term impacts on company's value creation capability were considered appropriate to be accounted for via amendments to the discount rate. If it was considered within the discount rate, then it did not enter the processes of forecasting earnings.

\subsubsection{Intellectual capital information and price multiples based valuation}

Price multiples based models were favoured by analysts for their simplicity, intelligibility and short term focus, and for enabling analysts to more easily communicate with their clients (see also, Imam et al., 2008). Multiples were catered to the alleged short term focus of fund managers, who tend to be remunerated on the quarterly performance of their portfolios relative to the market, as the market prices themselves reflect short term market perceptions and momentum. 
There are two main ways in which ICI seeps into price multiples-based valuations. First, it influences the forecast earnings/cash flows in a manner similar to how forecast earnings/cash flows in DCF models were manipulated. Second, the multiples that are applied to companies' forecast earnings/cash flows are adjusted to reflect the credibility of the management and market sentiment about the company, both of which are influenced by ICI. However, the sentiment is not limited to the value embodied in IC. Analyst Q (Industrial) noted that it is the role of an analyst to 'look through the sentiment and find the underlying value'.

A lot of the quantification comes under the heading of sentiment factors. People might say it is negative sentiment because these people haven't got their systems right or because management is hopeless or regulation is stacked against them. Even if you are not quantifying that, the fact is you're saying it's negative sentiment [and] you are going to put a discount on your multiples. (Analyst $\mathrm{R}$ - telecommunications)

The ease with which ICI could be incorporated by adjusting the multiples was seen as an advantage of price multiples based models over DCF models. However, as analysts used both these models in tandem it was necessary for the DCF-based valuation to be consistent with the multiples-based valuation. This was achieved by reverse engineering the DCF input parameters to reflect ICI from a target price derived using an IC-infused earnings multiple.

\subsection{Determination of the target price}

As with other components of the valuation process, analysts' views differed on the extent to which ICI influences price targets. Fourteen analysts explained that their price target flows directly from the valuation. They did not adjust the price target as they had either already factored in ICI through valuation model inputs or assumed that it has been captured in the reported earnings of the company. The difficulty of justifying IC-related alterations to the target price was one deterrent to adopting this mechanism for incorporating ICI. However, analysts identified four circumstances under which the price target could vary from the valuation as a result of ICI. The first is when there has been a change in the market sentiment of the company, inter alia, which may have resulted from a temporary change in company IC. The departure of a CEO is a common example that was quoted. The earnings forecast is not amended in such instances as the analyst did not foresee an impact on earnings but a mere change in the market sentiment that would affect the share price in the short term. If an impact on earnings was foreseen in addition to the changes in market sentiment, then adjustments are made to both the earnings forecast and the price target. 
Second, analysts who adopted more than one valuation model had the flexibility to incorporate the impact of ICI by selecting a price target from a range of price targets generated from alternative models to reflect the perceived impact.

It could definitely change your price target. So say you have a valuation range on four different methods of between \$1- \$2. If you had less faith in what was going on you would obviously apply less value to their intellectual capital; you would fall at the lower end of that range, as opposed to the higher end. (Analyst $\mathrm{G}$ - industrial)

The third circumstance was where the analyst applied a discount or a premium to price targets, determined on the basis of analysts' view of the company's IC. This approach was predominantly used when the impact of ICI was difficult to be quantified and incorporated through the models' inputs. Finally, some analysts attempted to explain the future impact that IC may have on the price target (i.e. rationalise the upside/downside potential associated with IC) rather than attempting to account for ICI through valuation models or the price target. The third and fourth approaches were advocated for their simplicity and intelligibility to investors, and for the difficulty in quantifying the impact of ICI.

\subsection{Justification and determination of the investment recommendation}

The recommendation generating processes varied between analyst firms. On one extreme were the analyst firms that had strict guidelines for determining the appropriate recommendation based on the magnitude of the difference between the current market price and target price. On the other end were those analysts who had freedom to exercise discretion when determining recommendations. These analysts considered ICI in the determination of the investment recommendation. Eight analysts acknowledged no role for IC in arriving at an investment recommendation.

Ten analysts explained that they would use IC to justify and/or adjust their recommendations. For example, Analyst $G$ (industrial) commented that management's track record could prompt a 'buy' recommendation for a company trading above intrinsic value, and Analyst B (materials) noted that an event like a CEO resignation can affect the recommendation without affecting the valuation. Also Analyst I (Industrial) commented:

It (ICI) should actually be inferred in (the) first case and put into the valuation. But sometimes it's not always possible to exactly quantify the impact of something that you are concerned about. ... (For example) you get the finance director resigning just before a result. It's a bad sign and so you would probably put a lot of caution on recommending that client in that 
situation. It's very hard to quantify by what [amount] a director leaving is going to impact on anything. ... (Analyst I - Industrial)

One reason for analysts' considering ICI at this final stage of the valuation process is the difficulty of quantifying ICI's impact on valuation model inputs. Also, ICI was considered at the recommendation stage by analysts who believed in keeping the valuation pure and scientific, and safeguarding its quantitative rigour. Analyst L (industrial) referred to this as adding a qualitative overlay on the recommendation. Analyst G (Industrial) noted:

What I do is highlight that risk (associated with some specific IC) as opposed to changing the valuation, so your valuation remains the same. ... you would highlight the risk that if staff are not happy and there is the potential for them to leave. If that did happen then they (the company) wouldn't achieve targets, and that is where they could end up. (Analyst G Industrial)

Notwithstanding any explicit consideration of IC in determining recommendations, ICI occupied an important role in justifying recommendations. One of the biggest factors influencing analysts' recommendations, irrespective of the sector of the company in question, is the human capital element of IC, and, more specifically, the quality of the management team. It was noted that a sell recommendation would primarily be due to a perception that management was not able to formulate or execute appropriate strategies to achieve long-term company growth.

I would never have a company on a sell unless I do not like the management team. My view of companies is very strictly run by key people within the firm, so it doesn't fit into any of the numbers. It very strongly influences the way I think about the company. So [ICI] doesn't influence the numbers but it does influence the way I think about the firm and their ability to leverage their business model. (Analyst P - Telecommunication)

Positive ICI was used to justify buy recommendations and intellectual liabilities were attributed to hold or sell recommendations when the difference between the current share price and the price target was trending in the opposite direction to the recommendation issued. Nonetheless, analysts were cautious in using IC to rationalise their recommendation as they perceived the actors in the financial market as being rational and logical and preferring hard quantitative analyses. Hence, when IC was used as a justification it had to form a convincing argument.

Analysts who did not consider ICI elsewhere in the valuation process discussed the impact of a possible change in IC as a risk factor in their scenario analysis, and acknowledged that their 
recommendation may not stand in the face of changes in company IC. Sometimes a recommendation which is automatically derived based on the direction and magnitude of the difference between the price target and the current market price may not be consistent with the recommendation based on the analyst's intuition. This can trigger a change in the analyst's assumptions and model parameters so as to reverse engineer the valuation from the analyst's intuitive recommendation.

\subsection{Client value addition}

Analysts considered that the real value they offer clients comes from the explanations they provide about how the valuation and recommendation were derived. Analysts believe that clients are more interested in the untold story than they are in the particular numbers produced by analysts.

Anyone can build a model and put some numbers to it but in this field qualitative matrices are basically the key drivers behind it - what the stocks are going to do, how the company is going to perform. (Analyst $\mathrm{E}$ - industrial)

The qualitative information in the most part concerns information about companies' IC. Discussion of company IC generally occurred more commonly when explaining the analysts' story about the company's value proposition. In fact, ICI was described as what made the analyst's story about the company interesting.

...otherwise all you talk about is anomalies and there's not much of a story about that. All the stuff that you talk about outside numbers and valuations is effectively intellectual capital or market shares or specific contracts. A lot of it is about management's ability to do what they say they can. The only way you can evaluate that is to make a call on intellectual capital issues. (Analyst Q - industrial)

The majority of analysts stated that ICI is sought by their institutional clients. ${ }^{7}$ The demand from them for ICI was driven by the need to justify to their own clients the reason for investing in a particular company, and to confirm their own view about the types of IC considered important. Management quality was identified as the most commonly discussed type of ICI in meetings with clients.

\footnotetext{
${ }^{7}$ Holland (2006) comments that fund managers have become increasingly interested in qualitative ICI and analysts are major source of this information. Whilst not directly attributable to IC, recent research evidence shows that analysts' industry knowledge (of which ICI is an integral part) is highly valued by analysts' clients (Brown et al., 2014).
} 
The types of ICI discussed varied by industry. For example, in the wealth management industry, human capital associated with fund managers, structural capital in the form of technological platforms and processes and relational capital, such as relationships with brokers were considered important talking points. Quality of personnel was important in relation to consulting firms. Structural capital, such as patents, was important in biotechnology companies, and brand and domain names were particularly relevant for internet and retail sectors. Retail sector analysts saw clients demanding information about relational capital, such as customer and supplier satisfaction and service levels, and structural capital, such as business processes.

Analysts consider private client meetings to be the most appropriate setting for client value addition through the provision of further insights on the analysed company. Private client meetings were preferred over sell-side reports for several reasons. First, ICI such as management quality was viewed as too sensitive a topic to be opining about in a sell-side report for the fear of reprisal by company management. Second, it was considered that too much emphasis on ICI in a report that explains the valuation would compromise the perceived rigour of analysts' quantitative analysis. This was also associated with perceived threats to analysts' credibility and the strict compliance regimes of US institutional investors. Third, it was difficult to articulate in a report some IC elements due to the analyst's lack of detailed knowledge about them. Related to this was the fact that company ICI as a whole was encapsulated in the analyst's view about the company, thus making it difficult to isolate specific types of ICI in a discussion. However, 17 analysts confirmed occasionally mentioning ICI in their reports.

\section{Conclusions}

This study has been able to address the paradox identified in some of the IC literature that despite the wide acceptance by the academic and accounting communities of the importance of IC to organisational success, sell-side analysts and other capital market participants are seen to be ambivalent to information about IC. The interviews with sell-side analysts reported in this study suggest that such paradox may in fact not exist. It reveals the non-trivial and multifaceted role of IC in analysts' stock valuation and investment recommendation decision making process. ICI was used: (1) to form analysts' perceptions of the overall quality, strengths and future prospects of the companies; (2) in valuation model selection decisions and in deriving valuation model inputs; (3) in setting price targets and making investment 
recommendations; and (4) as an important and integral element in analyst-client communications.

\subsection{Contributions}

This paper contributes to the valuation literature in relation to IC valuation in several ways. First, our analysis reveals the existence of a 'pecking order' of mechanisms for incorporating ICI in valuations by analysts, based on quantifiablity of the ICI signal. When the ICI is credible and quantifiable, analysts would use it explicitly in their multi-period forecasts of earnings/cash flows (both in DCF- and comparables-based valuations). The less quantifiable the ICI is, the less sophisticated and more judgmental is the mechanism of incorporating it in the valuation process. The next mechanism in the pecking order concerns arbitrary adjustments to the discount rate (in DCF models) or the benchmark multiple (in comparablebased models). Even less quantifiable ICI is reflected in the price target or recommendation, often bypassing the valuation models.

Second, this paper shows that IC valuation is not entirely an art but can also be grounded in valuation theory. On the artistic aspects of IC valuation, it is found that ICI helps analysts form an overall view about the company they analyse. Analysts use ad-hoc and subjective approaches in interpreting and transforming ICI into perceptions about companies, which are then used as an overlay on financial information. Also, the mechanisms for translating 'soft' ICI into quantitative valuation model inputs are implicit, ad-hoc, subjective and heuristic. Holland (2003) provides similar evidence on the use of ICI by buy-side analysts. In cases where ICI was less quantifiable, the analysts make quick adjustments to the valuation multiple or target prices, bypassing the judgemental process of translating IC into cash flow and earnings forecasts adaptations. Similar findings were reported by Holland (2006) for fund managers.

From the perspective of valuation theory, this paper reveals that there are designated entry points in to the valuation models for ICI. In DCF models ICI is captured in the earnings forecast or discount rate. The comparables-based models take account of ICI in the forecast earnings or earnings multiple. Also, there is a spectrum of approaches that analysts employ to adjust/moderate the price target to take account of ICI. One end of the spectrum displays analysts' boldness in explicitly acknowledging IC in price targets, e.g., by applying a premium or discount to a model-based value estimate. At the other end, analysts incorporate ICI into price targets either through the deliberate selection of a model that supports a 
preconceived IC-driven price target, or by embedding an element of uncertainty in the price target with an IC-based commentary.

Third, this study provides evidence of factors influencing analysts' mechanisms and rationales for dealing with ICI in company valuation. A number of analyst- and companyspecific characteristics, as well as the broader context of the analysts' decision making environment affect the extent and nature of analysts' ICI usage. These include (but not limited to): (1) analysts' attitudes towards, familiarity with, and background, knowledge and understanding of IC-type information; (2) analysts' beliefs about the market's and clients' understanding and perceptions of the relative importance and impact of IC on stock prices at a given point in time; (3) analysts' incentives to enhance their credibility among peers and clients by appearing 'scientific' through a demonstrable preference for quantifiable information and tacit use of 'soft' IC-type information; (4) size of the firm and the industry in which it operates; and (5) brokerage house-specific rules and heuristics.

This paper also contributes to analyst decision making literature. First, our findings indicate a need to redefine analysts' 'useful' information in line with Barker et al. (2012) so as to also include non-price sensitive information. It was found that the types of ICI accounted for by the mechanisms and rationales of analysts' valuations and recommendation was broad and varied. Most ICI was gathered through analysts' own efforts, and they relied less on company disclosed information for reasons discussed elsewhere in this paper. Management quality which is the primary and overarching IC attribute was entirely an analyst made construct. In fact, price-sensitive ICI played a very limited role within some of the analysts' valuation mechanisms as such information was considered to be partly factored in the market price.

Our results provide strong evidence that in their engagement with ICI, analysts do not act in an objectively rational (in a neoclassical economics sense) way. Instead, their decision making is cognitively bounded and highly contextual. Analysts' bounded rationality shows through when analysts equate IC with management quality, and perceive the potential of other elements of IC in creating value to be conditional on management quality. Management quality is as a screen through which analysts form views about how other elements of IC will create value in a company. Another overt manifestation of bounded rationality is direct incorporation of IC into recommendations and price targets in order to overcome the difficulty of converting ICI into measurable valuation model inputs. This paper paves the way to future research that would explore, theorise and rationalise analysts' use of ICI by adopting 
behavioural theories such as bounded rationality (Simon, 1947; March and Simon, 1958) and contextual rationality (March, 1978; Jones, 1999).

Our findings indicate that analysts are strategic users of ICI. They use IC as a rationale to reconcile their fundamental valuation with the current market sentiment towards the stock. Even when analysts believe that a particular IC change may not cause any changes in the company's fundamental value they still amend the price target or recommendation to get in line with the market's short-termism and current sentiment. As a result price targets may deviate from analysts' fundamental valuations. Another strategic use of ICI is seen in analysts' rationalisation of investment recommendations. ICI used for this purpose appears to be a function of its tractability. Also, the need to effectively communicate the valuation process and be seen as quantitatively and scientifically rigorous underlies the mechanisms employed by analysts in making the IC-value relationship transparent.

Our study provides evidence of the role of ICI in analyst-client meetings. Because of the importance of maintaining relationships with company management (Brown et al., 2014), analysts are reluctant to opine in their published reports about management quality or other IC issues which may be of a sensitive nature. Hence, how these important attributes of IC inform valuation and investment recommendation decisions remains opaque to the reader of analyst reports. Instead, this is conveyed and discussed with clients through analyst-client meetings. Analysts see real value addition to clients coming from the insights they provide at these meetings about the role of the less visible (IC) drivers to corporate value creation and to company valuations and recommendations.

\subsection{Implications}

Our findings have implications for financial analyst training providers, policy makers, companies and users of analyst reports. First, for training providers, this paper highlights the need to improve analysts' knowledge and awareness of IC-value relationships to enable better valuation of companies. Holland (2006) observes that buy-side analysts' use of IC in valuation is based on their experience in investee companies and how these companies used IC to exploit market conditions. We observe similar effects in respect to sell-side analysts, whereby analysts' prior experience and knowledge predicates their differential use of ICI in valuations. Indeed, Holland (2003) observes that buy-side analysts were only beginning to develop expertise in valuing intangibles and these practices would only be improved with 
continued trial and error, and experience. Our research also shows that some analysts do not have a clear understanding of the scope and nature of IC in company value creation. Therefore, it is important that further education is provided to analysts in this area. Thus financial analyst professional bodies (e.g., the CFA Institute, the Financial Services Institute of Australia, Associazione Italiana degli Analisti Finanziari) and universities should be called upon to offer training that includes modules on IC valuation.

Second, our findings should enable policy makers to determine analysts' possible reactions to potential regulations and guidelines stipulating the disclosure of ICI. Hence, this study informs policy setting in this area. Our study reveals that, similar to buy-side analysts (Holland et al., 2012), sell-side analysts do not experience a shortage of ICI. They do not feel a need for improved public disclosure due to several reasons. First, much of the ICI is perceived to be of proprietary in nature and its public disclosure prejudicial to companies. Second, as also highlighted in a report published by the Association for Investment Management and Research (AIMR) (2001), this kind of information can best be elicited in analyst-company meetings. Third, analysts consider that the quality of management is the most important element of IC (as it is for buy-side analysts; Holland and Johanson, 2003). Any disclosure of ICI by management would be fraught with self-reporting bias. Fourth, a more tacit, but arguably the most important, reason is analysts' self-interest. Analysts' competitive advantage as information searchers, processors and intermediaries is helped by their direct private access to company management (Holland and Doran, 1998). Disclosure of IC may erode this competitive advantage. Thus policy decisions intended to improve public disclosure of ICI ought to be justified from the point of view of retail investors who are not privy to analyst research. The utility of contemporary developments in integrated reporting, which incorporates IC reporting, should be evaluated in this light.

Third, this study should also be of interest to corporate disclosers, as it offers better understanding of how analysts are likely to react to and utilise, in their valuations and investment decisions, information about company IC. Our results indicate that companies can ensure that the incremental value resulting from IC investments can be incorporated in analysts' valuations by clearly articulating its impact on future earnings or cash flows. This would ensure that important ICI does not disappear in analysts' view of the firm, which may or may not affect the ultimate price target and recommendation. In order to reduce analysts' scepticism about company provided IC stories we show that it is important for companies to earn a track record of delivering results which are in line with forecasts, especially when such 
forecasts have been underpinned by IC changes. Our results suggest that a pre-condition for a better valuation of an IC-intensive company is for the company to create a perception of superior management quality. The discussion we provide on the mechanisms and rationales of analysts' use of ICI in firm valuation has implications for reducing the gap between capital markets' and companies' perception of IC valuation, and contributes towards an efficient valuation of IC-intensive companies.

Finally, for users of analyst reports, our results highlight the importance of being mindful of different approaches analysts use when accounting for ICI. Based on our findings, analyst reports can be categorised into three broad groups in terms of their treatment of ICI. The analyst reports in the first category assume company IC to be already incorporated in the earnings forecasts released by management. Only changes in company IC are explicitly dealt with in such reports. The second category includes analyst reports that specifically account for ICI explicitly and/or implicitly through various mechanisms explained earlier in this section. The analyst reports in the final category acknowledge the importance of ICI and provide a commentary of its potential impact, but they do not account for ICI in their valuations, price targets or recommendations. This latter approach seems to be placing on the investor the onus of interpreting the impact of ICI on firm value. These variations have implications particularly for institutional investors who rely on reports produced by different analysts. 


\section{References:}

Abhayawansa, S. \& Guthrie, J., 2010. Intellectual capital and the capital market: a review and synthesis. Journal of Human Resource Costing \& Accounting, 14 (3), 196-226.

Abhayawansa, S. \& Guthrie, J., 2012. Intellectual capital information and stock recommendations: Impression management? Journal of Intellectual Capital, 13 (3), $398-415$.

Abhayawansa, S. \& Guthrie, J., 2014. Importance of intellectual capital information: A study of Australian analyst reports. Australian Accounting Review, 24 (1), 66-83.

Aboody, D. \& Lev, B., 2000. Information Asymmetry, R\&D, and Insider Gains. Journal of Finance, 55 (6), 27-47.

Adhikari, A., Betancourt, L. \& Tondkar, R.H., 1998. The influence of culture and equity market development on financial analysts' perception of disclosure items in listing prospectuses. Advances in International Accounting, 11, 1-22.

Amir, E., Lev, B. \& Sougiannis, T., 2003. Do financial analysts get intangibles? European Accounting Review, 12 (4), 635-659.

Anderson, M.J., 1988. A comparative analysis of information search and evaluation behaviour of professional and non-professional financial analysts. Accounting, Organizations and Society, 13 (5), 431-446.

Ashton, R.H., 2005. Intellectual capital and value creation: a review. Journal of Accounting Literature, 24 (1), 53-135.

Asquith, P., Mikhail, M.B. \& Au, A.S., 2005. Information content of equity analyst reports. Journal of Financial Economics, 75 (2), 245-282.

Association for Investment Management and Research (Aimr), 2001. Submission to the SEC concerning the "fair disclosure" regulations. Charlottesville: Association for Investment Management and Research.

Ballester, M., Garcia-Ayuso, M. \& Livnat, J., 2003. The economic value of the R\&D intangible asset. European Accounting Review, 12 (4), 605-633.

Barker, R., 1998. The market for information - evidence from finance directors, analysts and fund managers. Accounting and Business Research, 29 (2), 3-20.

Barker, R., 2001. Institutional Investors, Accounting Information and the ASB. Edinburgh, Scotland: Institute of Chartered Accountants of Scotland.

Barker, R., Hendry, J., Roberts, J. \& Sanderson, P., 2012. Can company-fund manager meetings convey informational benefits? Exploring the rationalisation of equity investment decision making by UK fund managers. Accounting, Organizations and Society, 37 (4), 207-222.

Barker, R. \& Imam, S., 2008. Analysts' perceptions of 'earnings quality'. Accounting and Business Research, 38 (4), 313-329. 
Barker, R.G., 1999. The role of dividends in valuation models used by analysts and fund managers. European Accounting Review, 8 (2), 195-218.

Barth, M.E., Kasznik, R. \& Mcnichols, M.F., 2001. Analyst coverage and intangible assets. Journal of Accounting Research, 39 (1), 1-34.

Bence, D., Hapeshi, K. \& Hussey, R., 1995. Examining investment information sources for sophisticated investors using cluster analysis. Accounting and Business Research, 26 (1), 19-26.

Bouwman, M.J., Frishkoff, P.A. \& Frishkoff, P., 1987. How do financial analysts make decisions? A process model of the investment screening decision. Accounting, Organizations and Society, 12 (1), 1-29.

Bradshaw, M.T., 2002. The use of target prices to justify sell-side analysts' stock recommendations. Accounting Horizons, 16 (1), 27-41.

Bradshaw, M.T., 2004. How do analysts use their earnings forecasts in generating stock recommendations? The Accounting Review, 79 (1), 25-50.

Breton, G. \& Taffler, R.J., 2001. Accounting information and analyst stock recommendation decisions: a content analysis approach. Accounting and Business Research, 31 (2), 91101.

Brown, L. D., Call, A. C., Clement, M. B., \& Sharp, N. Y. (2014). Inside the "Black Box" of Sell-Side Financial Analysts. Journal of Accounting Research. DOI: 10.1111/1475679X.12067

Bukh, P.N., 2003. The relevance of intellectual capital disclosure: a paradox? Accounting, Auditing and Accountability Journal, 16 (1), 49-56.

Campbell, D. \& Slack, R., 2008. Narrative reporting: analysts' perception of its value and relevance. London: Association of Chartered Certified Accountants.

Campbell, D. \& Slack, R., 2011. Environmental disclosure and environmental risk: Sceptical attitudes of UK sell-side bank analysts. The British Accounting Review, 43 (1), 54-64.

Chan, L.K.C., Lakonishok, J. \& Sougiannis, T., 2001. The Stock Market Valuation of Research and Development Expenditures. Journal of Finance, 56 (6), 2431.

Clatworthy, M. \& Jones, M.J., 2008. Overseas equity analysis by UK analysts and fund managers. The British Accounting Review, 40 (4), 337-355.

Coram, P.J., Mock, T.J. \& Monroe, G.S., 2011. Financial analysts' evaluation of enhanced disclosure of non-financial performance indicators. The British Accounting Review, 43 (2), 87-101.

Core, J.E., 2001. A review of the empirical disclosure literature: discussion. Journal of Accounting and Economics, 31 (1-3), 441-456. 
Cuganesan, S., 2005. Intellectual capital-in-action and value creation: a case study of knowledge transformations in an innovation project. Journal of Intellectual Capital, 6 (3), 357-73.

Day, J.F.S., 1986. The use of annual reports by UK investment analysis. Accounting and Business Research, 16 (64), 295-307.

Demirakos, E.G., Strong, N.C. \& Walker, M., 2004. What valuation models do analysts use? Accounting Horizons, 18 (4), 221-240.

Demirakos, E.G., Strong, N.C. \& Walker, M., 2010. Does Valuation Model Choice Affect Target Price Accuracy? European Accounting Review, 19 (1), 35-72.

Dempsey, S.J. \& Gatti, J.F., 1997. The use of strategic performance variables as leading indicators in financial analysts' forecasts. Journal of Financial Statement Analysis, 2 (4), 61-80.

Diefenbach, T., 2009. Are case studies more than sophisticated storytelling?: Methodological problems of qualitative empirical research mainly based on semi-structured interviews. Quality and Quantity, 43, 875-894.

Dumay, J.C., 2009. Intellectual capital measurement: a critical approach. Journal of Intellectual Capital, 10 (2), 190 - 210.

Edvinsson, L. \& Sullivan, P., 1996. Developing a model for managing intellectual capital. European Management Journal, 14 (4), 356-364.

Flöstrand, P., 2006. The sell side - observations on intellectual capital indicators. Journal of Intellectual Capital, 7 (4), 457-473.

Flöstrand, P. \& Ström, N., 2006. The valuation relevance of non-financial information. Management Research News, 29 (9), 580-597.

Fogarty, T.J. \& Rogers, R.K., 2005. Financial analysts' reports: an extended institutional theory evaluation. Accounting, Organizations and Society, 30 (4), 331-356.

Francis, J., Olsson, P. \& Oswald, D.R., 2000. Comparing the accuracy and explainability of dividend, free cash flow, and abnormal

earnings equity value estimates. Journal of Accounting Research, 38 (1), 45-70.

Galanti, S., 2006. Which side are you on? How institutional positions affect financial analysts' incentives. Journal of Economic Issues, 40 (2), 387-94.

García-Meca, E. \& Martínez, I., 2007. The use of intellectual capital information in investment decisions: An empirical study using analyst reports. International Journal of Accounting, 42 (1), 57-81.

Hand, J. \& Lev, B., 2003. Intangible Assets: Values, Measures, and Risks Oxford: Oxford University Press.

Hirst, D.E., Koonce, L. \& Simko, P.J., 1995. Investor reactions to financial analysts' research reports. Journal of Accounting Research, 33 (2), 335-351. 
Ho, M.J. \& Harris, R.S., 2000. Brokerage analysts' rationale for investment recommendations: market response to different types of information. Journal of Financial Research, 23 (4), 449-468.

Holland, J., 2003. Intellectual capital and the capital market - organisation and competence. Accounting, Auditing and Accountability Journal, 16 (1), 39-48.

Holland, J., 2004. Corporate intangibles, value relevance and disclosure content. Edinburgh: Institute of Chartered Accountants of Scotland.

Holland, J., 2006. Fund management, intellectual capital, intangibles and private disclosure. Managerial Finance, 32 (4), 277-316.

Holland, J. \& Doran, P., 1998. Financial institutions, private acquisition of corporate information, and fund management. European Journal of Finance, 14 (2), 129-55.

Holland, J., Henningsson, J., Johanson, U., Koga, C. \& Sakakibara, S., 2012. Use of IC information in Japanese financial firms. Journal of Intellectual Capital, 13 (4), 562 581.

Holland, J. \& Johanson, U., 2003. Value-relevant information on corporate intangiblescreation, use and barriers in capital markets - "between a rock and a hard place". Journal of Intellectual Capital, 4 (4), 465-486.

Imam, S., Barker, R. \& Clubb, C., 2008. The use of valuation models by UK investment analysts. European Accounting Review, 17 (3), 503-535.

Imam, S., Chan, J. \& Shah, S.Z.A., 2013. Equity valuation models and target price accuracy in Europe: Evidence from equity reports. International Review of Financial Analysis, $28(0), 9-19$.

Jiang, X. \& Lee, B.S., 2005. An Empirical Test of the Accounting-Based Residual Income Model and the Traditional Dividend Discount Model. The Journal of Business, 78 (4), 1465-1504.

Johanson, U., 2003. Why are capital market actors ambivalent to information about certain indicators on intellectual capital. Accounting, Auditing and Accountability Journal, 16 (1), 31-38.

Kuzel, A., 1999. Sampling in qualitative inquiry. In Crabtree B \& M. W (eds.) Doing Qualitative Research (2nd Edition). Thousand Oaks, California: Sage, 33-45.

Lev, B., 2003. The measurement, valuation and reporting of intangible assets. Federal Reserve Bank of New York Economic Policy Review, 9 (3), 17-22.

Lev, B., Radhakrishnan, S. \& Zhang, W., 2009. Organization Capital. Abacus, 45 (2), 275298.

Lev, B. \& Sougiannis, T., 1996. The capitalization, amortization, and value-relevance of R\&D. Journal of Accounting and Economics, 21, 107-138. 
Livne, G., Simpson, A. \& Talmor, E., 2011. Do customer acquisition cost, retention and usage matter to firm performance and valuation? . Journal of Business Finance and Accounting, 38 (3/4), 334-363.

Lundholm, R.J. \& Sloan, R.G., 2004. Equity valuation and analysis with eVal New York: McGraw-Hill/Irwin.

Lye, J., Perera, H. \& Rahman, A., 2005. The evolution of accruals-based Crown (government) financial statements in New Zealand. Accounting, Auditing \& Accountability Journal, 18 (6), 784 - 815.

Mangena, M., Pike, R. \& Li, J., 2010. Intellectual capital disclosure practices and effects on the cost of equity caapital: UK evidence. Edinburgh: The Institute of Chartered Accountants of Scotland.

Meritum, 2002. Measuring intangibles to understand and improve innovation management. Brussels: European Commission.

Miles, M.B. \& Huberman, A.M., 1994. Qualitative Data Analysis (2nd ed.) Thousand Oaks, California: Sage.

Mouritsen, J., 2003. Intellectual capital and the capital market: the circulability of intellectual capital. Accounting, Auditing and Accountability Journal, 16 (1), 18-30.

Murthy, V. \& Mouritsen, J., 2011. The performance of intellectual capital: Mobilising relationships between intellectual and financial capital in a bank. Accounting, Auditing \& Accountability Journal, 24 (5), 622-646.

Nagar, V. \& Rajan, M.V., 2001. The Revenue Implications of Financial and Operational Measures of Product Quality. The Accounting Review, 76 (4), 495-513.

Nielsen, A.C., 2008. A content analysis of analyst research: health care through the eyes of analysts. Journal of Health Care Finance, 34 (3), 66-90.

Ohlson, J.A., 1995. Earnings, book values, and dividends in equity valuation. Contemporary Accounting Research, 11 (2), 661-87.

Olbert, L., 1994. Stock valuation methods of financial analysts in a thin stock market in Sweden, with comparison to the United Kingdom and the United States. International Journal of Accounting, 29 (2), 123-135.

Orens, R. \& Lybaert, N., 2007. Does the financial analysts' usage of non-financial information influence the analysts' forecast accuracy? Some evidence from the Belgian sell-side financial analyst. International Journal of Accounting, 42 (3), 237271.

Orens, R. \& Lybaert, N., 2010. Determinants of sell-side financial analysts' use of nonfinancial information. Accounting and Business Research, 40 (1), 39-53.

Palepu, K.G., Healy, P. \& Peek, E., 2013. Business Analysis and Valuation: IFRS Edition Text and Cases (3rd Edition): Cengage Learning. 
Peasnell, K.V., 1982. Some formal connections between economic values and yields and accounitng numbers. Journal of Business Finance and Accounting, 9 (3), 361-381.

Penman, S., 2009. Accounting for intangible asets: There is also an income statement. ABACUS, 45 (3), 358-371.

Penman, S., 2012. Financial Statement Analysis and Security Valuation (5th Edition) New York: McGraw-Hill.

Penman, S.H. \& Sougiannis, T., 1998. A Comparison of Dividend, Cash Flow, and Earnings Approaches to Equity Valuation*. Contemporary Accounting Research, 15 (3), 343383.

Previts, G.J., Bricker, R.J., Robinson, T.R. \& Young, S.J., 1994. A content analysis of sellside financial analyst company reports. Accounting Horizons, 8 (2), 55-70.

Qu, S.Q. \& Dumay, J., 2011. The qualitative research interview. Qualitative Research in Accounting \& Management, 8 (3), 238-264.

Rajgopal, S., Shevlin, T. \& Venkatachalam, M., 2003. Does the Stock Market Fully Appreciate the Implications of Leading Indicators for Future Earnings? Evidence from Order Backlog. Review of Accounting Studies, 8 (4), 461-492.

Robb, S.W.G., Single, L.E. \& Zarzeski, M.T., 2001. Nonfinancial disclosures across AngloAmerican countries. Journal of International Accounting, Auditing and Taxation, 10 (1), 71-83.

Sakakibara, S., Hansson, B., Yosano, T. \& Kozumi, H., 2010. Analysts' perceptions of intellectual capital information. Australian Accounting Review, 20 (3), 274-285.

Schipper, K., 1991. Analysts’ forecasts. Accounting Horizons, 5 (5), 105-121.

Society for Knowledge Economics [Ske], 2007. Intangible drivers of organisational productivity and prosperity: international trends and developments in extended performance management, measurement and reporting. Crows Nest: SKE.

Stewart, T.A., 1997. Intellectual Capital: The New Wealth of Organizations New York: Doubleday Business.

Sveiby, K.E., 1997. The New Organisational Wealth: Managing and Measuring Knowledge Based Assets San Francisco: Berrett-Koehler.

Thomas, A., 2003. A tale of two reports. European Business Forum, 16 (Winter), 79-81.

Twedt, B. \& Rees, L., 2012. Reading between the lines: An empirical examination of qualitative attributes of financial analysts' reports. Journal of Accounting and Public Policy, 31 (1), 1-21.

Vanstraelen, A., Zarzeski, M.T. \& Robb, S.W., 2003. Corporate non-financial disclosure practices and financial analyst behaviour across three European countries. Journal of International Financial Management and Accounting, 14 (3), 249-278. 
Wyatt, A., 2008. What financial and non-financial information on intangibles is valuerelevant? A review of the evidence. Accounting and Business Research, 38 (3), 217256. 
Figure 1: A framework of analysts' use of intellectual capital information

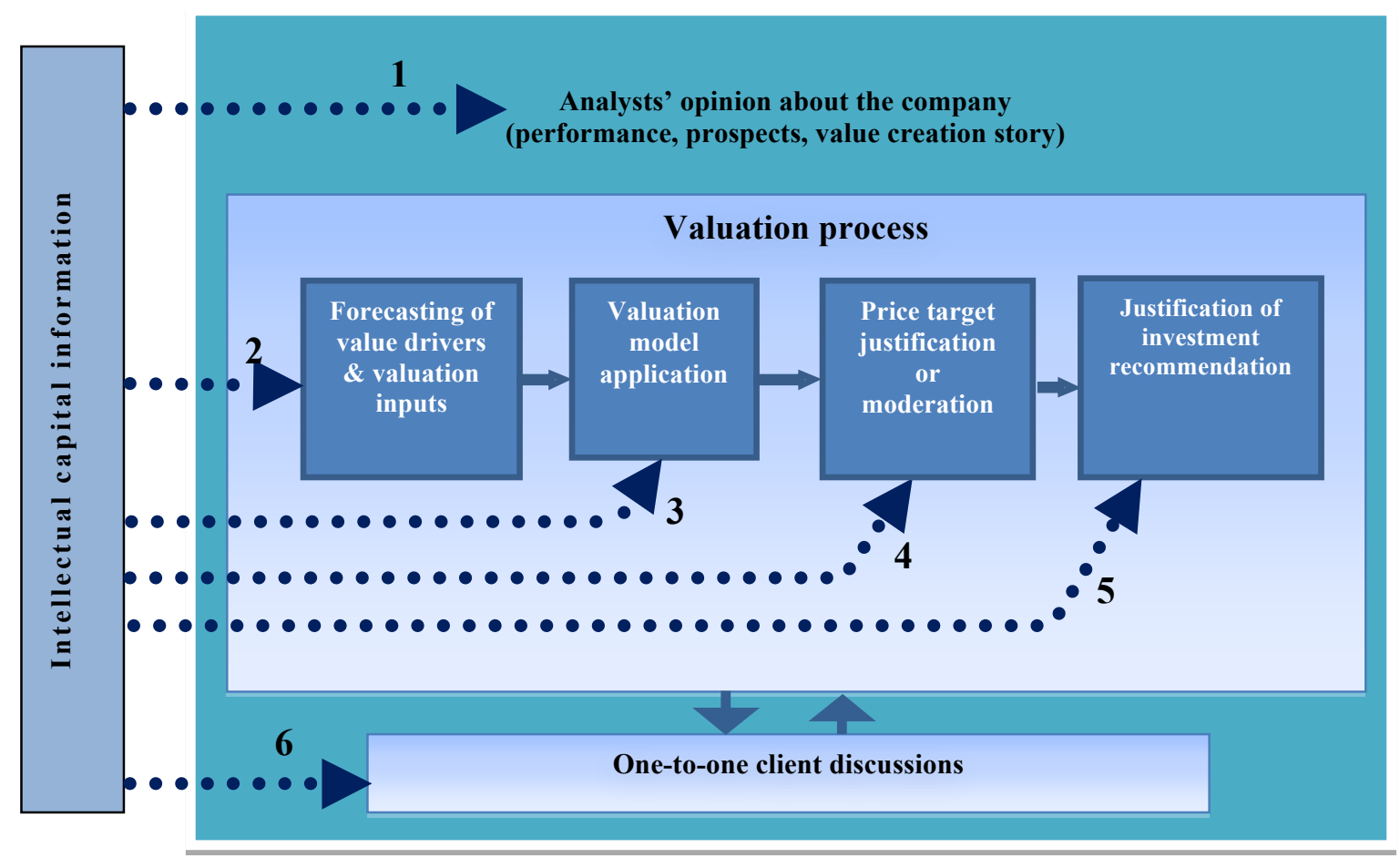

